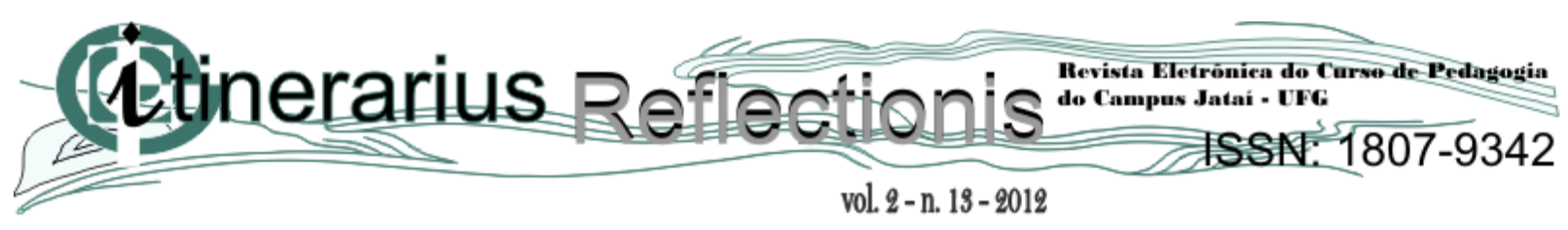

\title{
ANÁLISE DOS MÉTODOS EDUCACIONAIS NO BRASIL: DESCOBRIMENTO AO FINAL DO IMPÉRIO
}

\author{
Elenilson de Vargas Fortes Instituto Federal de \\ Educação, Ciência e Tecnologia de Goiás - IFG. \\ vargasfortes@yahoo.com.br
}

\begin{abstract}
RESUMO: Atualmente, o Brasil possui diversos problemas na educação. Esses problemas se estendem por toda estrutura educacional Brasileira, pois há necessidade de mais investimentos neste setor. Por outro lado, a trajetória de países desenvolvidos sempre está conectada a uma educação de qualidade. Portanto, por que não fazer o mesmo no Brasil? Por que no Brasil não há políticas educacionais concretas que realmente funcionem? Este trabalho busca responder estes questionamentos através de uma revisão bibliográfica de autores que descrevem toda trajetória educacional no Brasil, desde seu descobrimento, no período jesuítico, até o final do Império. Mostrou-se que o tratamento dado à educação no Brasil durante este período foi determinante, influenciando os rumos da educação brasileira na atualidade.
\end{abstract}

Palavras-chave: Educação Brasileira. Ensino. Políticas Educacionais. Métodos educacionais.

ABSTRACT: Currently, Brazil has a lot of problems in education. These problems extend to all Brazilian educational structure, since there is the necessity need for higher investments in this sector. On the other hand, the trajectory of developed countries is always connected to a quality education. So, why not to do the same in Brazil? Why are there not any specific educational policies in Brazil that really work? This paper attempts to answer these inquires through a literature review of authors who described the educational trajectory in Brazil, since its discovery, the Jesuit period, until the end of the Empire. It was shown that the treatment given to education in Brazil during the Empire period was decisive, influencing the directions of Brazilian education today.

Keywords: Brazilian Education. Teaching. Educational Policies. Educational methods.

\section{Introdução}

A atual educação brasileira, como já é de conhecimento da maioria da população, não é nem de longe um exemplo de qualidade e se quer está entre as melhores se comparada com os outros países. Há dados que apontam que o Brasil, está muito aquém de possuir um ensino público de qualidade. Atualmente o Brasil é sexta economia do mundo, porém de 


\section{(atinerarius Re , (1)

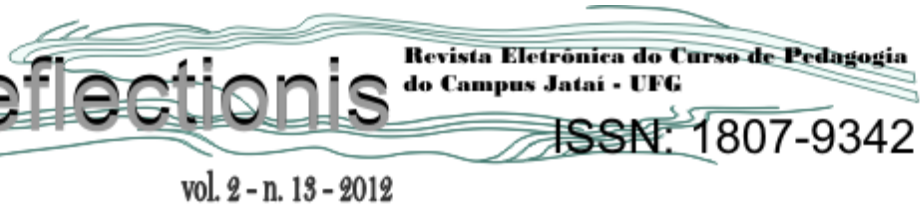

acordo com folha online ${ }^{1}$, o "Brasil fica no $88^{\circ}$ lugar em ranking de educação da UNESCO". Há de se convir que isto não seja agradável. Por exemplo, o Brasil se encontra atrás de países como Paraguai e Bolívia que nem de longe possuem o PIB do Brasil. O que está errado? Falta mais investimento na educação? Infraestrutura? Condições de trabalho? Remuneração compatível?

Certamente, todos esses questionamentos elencados no parágrafo anterior interferem na educação. Por outro lado, não é difícil de encontrar países que foram destruídos por guerras e catástrofes e que foram reconstruídos através de uma educação com qualidade. O Japão é um exemplo. Por que não adotar os mesmos procedimentos educacionais no Brasil? Este artigo colabora no sentido de identificar um dos motivos que induzem o país a não possuir atualmente uma educação de qualidade.

Timidamente, nos últimos anos, houve no Brasil alguns avanços na tentativa de tentar modificar este quadro. Dentre eles, pode-se citar, por exemplo, a Lei de Diretrizes e Bases da Educação (LDB) e a criação do Plano Nacional de Educação (PNE). Além disso, atualmente se discute destinar 10\% do PIB para educação, o que em tese seria ótimo. Existem também, algumas avaliações sistemáticas que são realizadas no Brasil com o intuito de medir a qualidade da educação no país, como por exemplo, a Prova Brasil e o Sistema Nacional de Avaliação da Educação Básica (Saeb). As informações obtidas através destes mecanismos de avaliações são sintetizadas em números. Esses dados são apresentados através do Índice de Desenvolvimento da Educação Básica (Ideb). Há ainda o Exame Nacional de Desempenho de Estudantes (Enade), que funciona de forma análoga ao Ideb, pois também serve para avaliar a qualidade da educação superior no país. Evidentemente, todo e qualquer método ou esforço na tentativa de modificar o quadro citado acima é aceitável, já que as bases de uma nação desenvolvida se constroem a partir de educação com qualidade. Como explicar então, essa falta de qualidade na educação brasileira?

Há uma importante variável que certamente influenciou nos rumos da educação no Brasil, sua colonização. Entender o contexto histórico de como foi à educação brasileira

\footnotetext{
${ }^{1}$ Disponível em: <http://www1.folha.uol.com.br/saber/882676-brasil-fica-no-88-lugar-em-ranking-de-educacaoda-unesco.shtml>. Acesso em: 14 set. 2012.
} 
desde o período colonial, nos dará uma pista do porquê de tantos problemas que o Brasil possui atualmente na educação. Segundo Karina (2009),

\begin{abstract}
O estudo da educação a partir de um contexto histórico é importante, pois nele estão juguladas as raízes do presente. A educação de cada povo surge através de sua história como uma cultura que prevalece com o decorrer do tempo. Portanto, é importante também resgatar a história da educação, para que possamos abranger a época moderna.
\end{abstract}

Veja que "a educação de cada povo surge através de sua história como uma cultura que prevalece com o decorrer do tempo", ou seja, analisando a conjuntura histórica da educação brasileira, esta poderá fornecer dados para se analisar os problemas atuais. Portanto, entender o porquê de se ter hoje uma educação questionável no Brasil, poderá estar correlacionado com a forma com o que a educação brasileira foi tratada nos séculos passados.

Só para se ter uma ideia de como era complicada a educação no Brasil, Cunha (2007), descreve que

A primeira universidade do continente americano surgiu em São Domingos, em 1538 (...). Em 1553 foi inaugurada no México a segunda Universidade americana (...). Vieram depois a Universidade de São Marcos (Peru), de São Felipe (Chile), Córdoba (Argentina), e outras, de modo que, ao tempo, de nossa, independência, havia 26 ou 27 Universidades na América Espanhola (CUNHA, 2007 apud TEIXEIRA, 1969, pg. 244).

Enquanto isso, Cunha (2007) afirma que não surgiu, no mesmo período, nenhuma Universidade no Brasil. Além disso, Cunha (2007, pg. 16) explica o não surgimento de Universidades no Brasil alegando que "Portugal bloqueava o desenvolvimento do ensino superior no Brasil, de modo que mantivesse a colônia incapaz cultivar e ensinar as ciências, as letras e as artes”. Isto é, manter o povo na ignorância, a fim de controlá-los. Porém, como explicar o surgimento de tantas Universidades nas colônias Espanholas e nenhuma no Brasil? Basta analisar a quantidade de Universidades que existiam na Espanha na época, oito no total, enquanto isso, em Portugal existia apenas a Universidade de Coimbra, (CUNHA, 2007, pg. 17), de modo que essas Universidades eram fonte de mão de obra para abertura de cursos superiores na colônia, daí o motivo de tantas universidades nas colônias Espanholas e nenhuma no Brasil.

Esses obstáculos que eram impostos ao Brasil foram sem dúvida um dos principais gargalos da educação brasileira na época e perduram até hoje. Desde a época 


\section{(titinerarius 201 \\ vol. 2-n. 13-2012 \\ Revista Eletróniéa do Curse de Pedagogia

Jesuítica e mesmo após a independência, a educação no Brasil nunca foi prioridade, ficando a educação sempre a cargo das elites do país. Esses problemas serão claramente evidenciados nas seções seguintes através de estudos feitos por meio de revisão bibliográfica no período que compreende desde o início da colonização do Brasil, por volta de 1550, até o final do império, em 1889. As principais referências utilizadas neste artigo foram: Azevedo (1971), Cunha (2007), Cunha (2005), Paiva (2007), Saviani (2007), Ribeiro (2006), Zotti (2004) através do qual foi descrito os principais métodos educacionais implementados no Brasil desde os jesuítas até final do reinado de Dom Pedro II com publicação do Decreto $n^{\circ} 7.247$ de 19 de Abril de 1879, proposto pelo então Ministro Carlos Leôncio de Carvalho.

Este trabalho está divido em seis seções disposto na seguinte ordem: Introdução, Período Jesuítico, Período Joanino, Período Pombalino, Período Imperial com ênfase no Ensino Primário no Império. Aliás, optou-se em descrever a última seção somente pelo ensino nas séries iniciais no Império por este autor entender que educação primária é o alicerce das futuras gerações de alunos do país e que base educacional de uma nação se constrói através de uma educação de qualidade, principalmente nas séries iniciais. Entretanto, futuros trabalhos de pesquisa poderão abordar a educação secundária e superior no Brasil Império.

\section{Período Jesuítico}

Este período da história em que os Jesuítas foram responsáveis pela educação da colônia durou de 1549 a 1759. Não há durante este período políticas educacionais executadas em nosso país, apenas alguns métodos primitivos e feudais implantados pelos Jesuítas. Os motivos são mais variados possíveis. Só para citar um exemplo, o Brasil foi colonizado para ser uma colônia extrativista (exploração), isto é, os descobridores estavam interessados em extrair nossos recursos naturais, como ouro e a madeira, e não em métodos educacionais que conscientizassem a população. Além do mais, estes habitantes eram formados basicamente por índios (nativos) e escravos e o principal objetivo inicial dos Jesuítas era instruir e converter os indígenas e/ou escravos ao catolicismo. Paiva (2003, pg. 66) retrata este período da história afirmando que "o governo português resolvera adotar uma nova política 


\section{Ctinerarius 215 \\ vol. 2-n. 13-2012 \\ Revista Eletróniéa do Curse de Pedagogia

colonizadora em relação ao Brasil, reconhecia-se a conversão dos indígenas à fé católica pela catequese e instrução como atividade prioritária para o êxito da colonização portuguesa".

Da mesma forma, Ribeiro (2007, pg. 23) reforça esta teoria dizendo que "o plano legal (catequizar e instruir os índios) e o plano real se distanciam. Os Instruídos serão descendentes dos colonizadores. Os indígenas serão apenas catequizados”. Isto indica que a educação na colônia basicamente se limitava, em seus primórdios, somente na "conversão dos indígenas" como forma de obter mão de obra para exploração do imenso território descoberto. Afinal, a Europa passava por um momento de mudanças profundas na Igreja Católica por meio da Reforma Protestante, iniciada por Martinho Lutero no século XVI e "do ponto de vista religioso, interessava a Companhia como fonte de novos adeptos do Catolicismo", (RIBEIRO, 2007, pg. 23), ou ainda, como Maria Luisa Santos Ribeiro afirma formavam-se "guerreiros de cristo", (pg. 25).

A Educação Jesuítica pode ser dividida em duas fases. Segundo Saviani (2006, pg. 10), “o primeiro período (...) iniciou com a chegada dos primeiros Jesuítas, em 1549, e se estendeu até 1599, quando entrou em vigor o ratio studiorum ${ }^{2}$ ". O segundo período, de acordo com o Dermeval Saviani, "correspondeu à organização dos estudos conforme as regras do ratio studiorum, cuja vigência se estendeu até a expulsão dos Jesuítas em 1759”, (pg. 10). O primeiro período teve forte influência do Padre Manuel da Nóbrega ${ }^{3}$. A Figura 1 exibe um plano de estudo de como era representada esta estrutura educacional no Brasil Colônia. Observe que este plano de ensino é descrito da seguinte forma: Até a morte de Nóbrega e após de morte de Nóbrega, evidenciando que até 1570, ano de sua morte, Nóbrega implantou uma metodologia distinta da orientação contida no Ratio, o que indica que provavelmente este entrava em "choque com a própria ordem religiosa", (RIBEIRO, 2007, pg. 22), já que após sua morte a metodologia utilizada por Nóbrega foi abandonada.

\footnotetext{
${ }^{2}$ Ratio Studiorum é uma espécie de coletânea privada, fundamentada em experiências acontecidas no Colégio Romano e adicionada a observações pedagógicas de diversos outros colégios, que busca instruir rapidamente todo jesuíta docente sobre a natureza, a extensão e as obrigações do seu cargo (...). Constituiu-se numa sistematização da pedagogia jesuítica contendo 467 regras cobrindo todas as atividades dos agentes diretamente ligados ao ensino e recomendava que o professor nunca se afastasse em matéria filosófica de Aristóteles, e teológica de Santo Tomás de Aquino. Disponível em: <http://pt.wikipedia.org/wiki/Ratio_Studiorum. Acesso em: 11 set. 2012>.

${ }^{3}$ Jesuíta português, Manuel da Nóbrega nasceu em Sanfins do Ouro em 18 de outubro de 1517; e faleceu em 18 de outubro de 1570, no Rio de Janeiro. Foi chefe da primeira missão jesuítica da América. Disponível em: <http://www.historiabrasileira.com/biografias/manuel-da-nobrega/>. Acesso em: 11 set. 2012.
} 


\section{(titinerarius Refioctions: $=$ (t)}

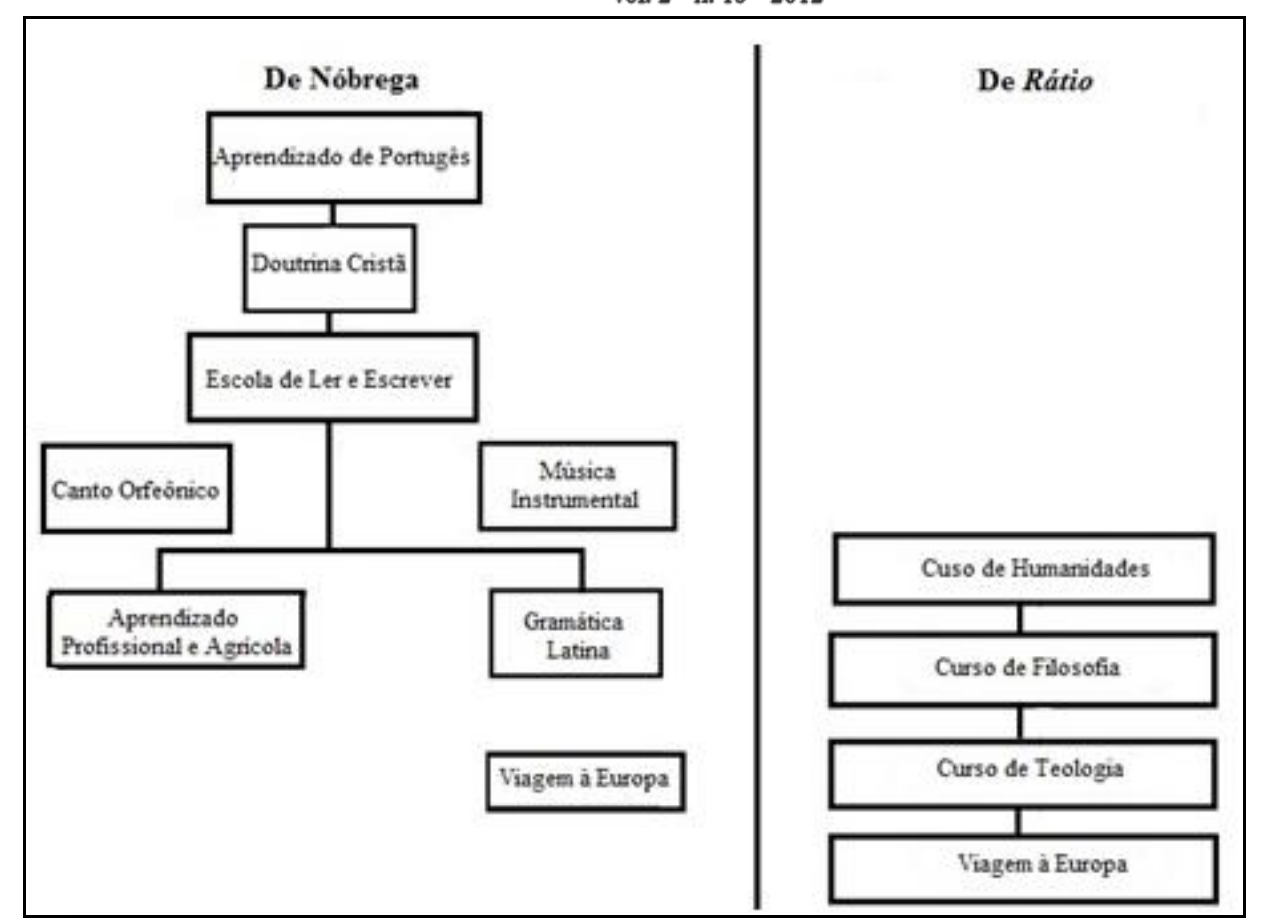

Figura 1: Plano de Estudos: Durante a vida de Nóbrega e após sua morte.

Fonte: Figura adaptada de Ribeiro (2007, pg. 23).

Veja que as estruturas educacionais proposta tanto por Nóbrega ou pelo Rátio são rudimentares, se limitando apenas, em geral, em técnicas de leitura e escrita. Além do mais, não existia infraestrutura, condições sociais ou políticas econômicas neste período, e tão pouco, a coroa portuguesa estava interessada no "problema educacional da colônia", (PAIVA, 2003, pg. 68).

Com a morte de Nóbrega, prevaleceu o Rátio. Cunha (2007, pg. 29) mostra mais detalhes de como estava disposto o ensino na colônia: "nos colégios Jesuítas no Brasil havia quatro graus de ensino sucessivos e propedêuticos: $\mathrm{O}$ curso Elementar, o curso de Humanidades, o curso de Artes e o curso de Teologia". Além disso, Cunha (2007, pg. 29) afirma que nestes "quatro graus de ensino", o aluno estudava aproximadamente 10 anos e que os mesmos estavam dispostos da seguinte forma: "o curso Elementar" era aquele que ensinava o indivíduo a "ler, escrever e contar". É como se fossem hoje as séries iniciais do Ensino fundamental. O "curso de Humanidades" instruía o sujeito na "Gramática, Retórica, das Humanidades, sendo realizado todo em latim". O "curso de Artes" era também conhecido como "Ciências Naturais" e abrangia o ensino de "lógica, física, matemática, ética e 


\title{
Etinerarius Refiectionis YH. \\ vol. 2-n. 13-2012

metafísica". Por fim, o "curso de Teologia" baseava-se no estudo dos ideais da "Teologia Moral" e do "dogma católico".

Segundo Paiva (2003, pg. 66) os Jesuítas "multiplicaram as escolas de ler e escrever, instaladas em São Vicente, Bahia, Espírito Santo e Pernambuco; Organizaram-se pouco a pouco - classes de gramática e colégios; instituiu-se o ensino profissional e, mais tarde, surgiram os seminários". Portanto a de se convir que mesmo com infraestrutura arcaica na colônia os Jesuítas, pouco a pouco, conseguiram instituir um sistema educacional no Brasil.

Além disso, Paiva (2003, pg. 68) ainda afirma que

\begin{abstract}
além das escolas de ler e escrever, os jesuítas mantinham diversos seminários e 24 colégios para a formação das elites. Na verdade, as condições econômicas, sociais e políticas da colônia - e a forma com que elas evoluíram - não favoreciam o desenvolvimento de um sistema educacional popular, nem propiciavam grande interesse pelo problema educacional. Consolidada a colonização portuguesa, tratavase então de um preparar e formar religiosos, de educar uma parte das elites, a fim de assegurar a continuidade do que já fora conquistado.
\end{abstract}

Veja que, conforme Vanilda Paiva (2003) expõe, há um interesse de "preparar e formar religiosos, de educar uma parte das elites, a fim de assegurar a continuidade do que já fora conquistado". Da mesma forma, Ribeiro (2007, pg. 27) afirma que "os melhores alunos eram os escolhidos para cursarem Teologia e tornarem-se futuros membros da Companhia de Jesus". Afinal, muitos dos alunos que formavam nos colégios Jesuítas não iam para Europa estudar, mas adquiriram gosto pelo clero e acabavam dispersando a doutrina Jesuítica, o que em tese era ótimo sob a ótica dos Jesuítas. Além dos Jesuítas, os “franciscanos preocuparamse também com a conversão dos indígenas, dedicando-se principalmente ao ensino de trabalhos manuais", (PAIVA, 2003, pg. 67).

Em relação ao funcionamento destes colégios, Cunha (2007, pg. 31) descreve que

funcionavam seis dias por semana, cinco horas por dia, em dois expedientes. Em geral, havia duas horas de aula pela manhã, das 8 às 10 horas, seguidas de meia hora de discussão de dúvidas; o mesmo a tarde, das 15 às 17 horas, mais meia hora. Havia um período longo de férias anuais nos meses de dezembro a janeiro, além dos períodos mais curtos, distribuídos ao longo do ano.

Pode-se dizer que estes colégios possuem semelhanças com atuais em funcionamento no Brasil, principalmente no que tange as horas estudas e o recesso escolar. O 


\section{(tivinerarius 20}

primeiro colégio Jesuíta fundado em terras Brasileiras ocorreu na Bahia, em 1550. No ano de 1553, inaugura-se o curso de "Humanidades" e em 1572 "Artes e Teologia" (CUNHA, 2007, pg. 31). Como exemplo, a Tabela 1 exibe a quantidade de alunos matriculados em colégio jesuíta na Bahia em 1589. A expressão "de casa” se refere aos alunos que se preparavam para serem sacerdotes. Enquanto que os "externos" são de alunos que poderiam pertencer a outras religiões, (CUNHA, 2007, pg. 32).

\begin{tabular}{l|l|l|l}
\hline \multirow{2}{*}{ Curso } & \multicolumn{3}{|l}{ Números de Estudantes } \\
\cline { 2 - 4 } & De casa & Externos & Total \\
\hline Elementar & $\ldots$ & $\ldots$ & 120 \\
\hline Humanidades & 2 & 55 & 57 \\
\hline Artes & 8 & 16 & 24 \\
\hline Teologia & 4 & 11 & 15 \\
\hline Total & $\ldots$ & $\ldots$ & 216 \\
\hline
\end{tabular}

Tabela 1: Total de alunos matriculados na Bahia no ano 1589.

Fonte: (CUNHA, 2007, pg. 32 apud LEITE, pg. 81 - 82).

Dentre os cursos superiores que os Jesuítas ofertaram no Brasil destaca-se o curso de "Filosofia" criado em 1638 no Rio de Janeiro, o "curso de Teologia" no Maranhão em 1688, o "curso de Filosofia" em Santos em 1708, o curso de "Teologia" em Piratininga. Havia também cursos superiores no "Colégio de Olinda" e o "Curso de Artes no Pará" criado em 1695, (CUNHA, 2007, pg. 35 - 38).

A influência Jesuítica chegou a tal ponto na colônia que "10\% de toda arrecadação dos dízimos reais (impostos), em todas as capitanias da colônia e seus povoados, ficavam para sempre vinculados à manutenção e sustento dos colegas Jesuíticos”, (RIBEIRO, 2007, pg. 28). Além disso, tal controle era tão predominante que a Companhia de Jesus, conseguia inclusive, decidir sobre a educação dos filhos dos senhores de engenho. Pois "o terceiro filho deveria seguir a vida religiosa, o primeiro seria herdeiro e o segundo, o letrado", (RIBEIRO, 2007, pg. 28). Como será descrito a seguir, este poder obtido pelos Jesuítas na colônia vai acabar influenciando na expulsão dos mesmos.

Se não bastasse a forte influência adquirida pelos Jesuítas, circulavam pela Europa as ideias iluministas. Segundo Paiva (2003, pg. 68), estas ideias "estavam chegando a Portugal. Temia-se a influência das ideias liberais europeias que, em outros países americanos, começavam a provocar revoltas e desejos de emancipação, o sistema escolar 
poderia ser veículo dessas ideias”. Na metade do século XVIII, entre 1740 e 1750, teve início

o desmantelamento de toda estrutura de ensino arquitetado pelos Jesuítas na colônia. As ideias iluministas influenciaram Portugal a mudar seu sistema de ensino. Mais tarde, através de uma reforma arquitetada pelo "Marquês de Pombal" os Jesuítas foram expulsos da colônia em 1759 e tem-se o início do Período Pombalino.

\section{Período Pombalino}

Segundo Zotti (2004, pg. 25), este período teve como principal objetivo a "modernização do ensino e da cultura Portuguesa". Havia um objetivo claro na época de formação apenas dos nobres, de forma a atender os interesses do Estado. Solange Aparecida Zotti descreve que Pombal não tinha "intento antirreligioso" (pg. 25), mas almejava a princípio a modernização dos métodos de ensino que estavam em vigor, a fim de atualizar o Estado arcaico em que se encontrava Portugal com seus métodos de ensinos feudais.

Portugal encontrava-se nesta época completamente destruído após o domínio Espanhol que ocorreu de 1580 a 1640, (RIBEIRO, 2007, pg. 30). "Sua marinha estava destruída, seu império colonial esfacelado (...). Estava definitivamente perdido para Portugal o comércio asiático (...). Só lhe sobraria o antigo império ultramarino, o Brasil, e algumas posses da África”, (PRADO JÚNIOR, 1969, pg. 49).

Diante da iminente reforma econômica que Portugal necessitava, Zotti (2004, pg. 25) assinala "pelo menos três novos objetivos da nova política econômica portuguesa":

1) Incentivo às manufaturas na metrópole e proibindo as mesmas na Colônia, para que se constituísse uma reserva de mercado; 2) Incentivo à acumulação de capital, tanto na metrópole como nas colônias; 3)Substituição das ideologias características da sociedade feudal por outras, de acordo com a orientação da sociedade capitalista.

O item 3) por sinal revela as "reformas educacionais" que Pombal pretendia impor em Portugal e na Colônia, isto é, um modelo educacional focado no modelo capitalista. Estas ações desencadearam adiante a expulsão dos Jesuítas, já que como frisado anteriormente os Jesuítas se baseavam em modelo educacional arcaico e feudal. Outra questão que pesava

${ }^{4}$ Informações acerca de Pombal podem ser obtidas em: <www.pedagogiaemfoco.pro.br/heb03.htm>. Acesso em: 27 ago. 2012. 


\section{(titinerarius 201 \\ vol. 2-n. 13-2012 \\ Revista Eletróniéa do Curse de Pedagogia

em desfavor dos Jesuítas baseava-se no fato de que as reformas eminentes propostas por Pombal tinham como base ideológica o Iluminismo. Segundo Cunha (2007, pg. 43) “o século XVIII foi chamado, pelos seus contemporâneos, de século das luzes, em oposição à era das trevas, à Idade Média”. Ou seja, Pombal concebido de ideias iluministas procuraria desvincular a educação dos Jesuítas, já que os mesmo possuíam fortes ligações com a igreja Católica. Além disso, Cunha (2007, pg. 44) ainda afirma que o iluminismo "consistia na celebração da razão em oposição a qualquer religião revelada, consistente com a fé na ordem racional do mundo, a exaltação da ciência experimental e da técnica".

Portanto, Pombal baseado no Iluminismo e no Estado autoritário, arquiteta uma reforma que "contrapõem ao predomínio das ideias religiosas e, com base nas ideias laicas inspiradas no iluminismo, instituem o privilégio do estado em matéria de instituição surgindo, assim, a nossa versão da educação pública estatal” (SAVIANI, 2006, pg. 17).

Se não bastasse, Zotti (2004, pg. 26) afirma que "a Companhia de Jesus mantinha uma postura de insubordinação ao rei e a educação possuía características medievais". Isto era muito desfavorável aos Jesuítas, já que para as reformas políticas de Pombal funcionassem, a educação deveria ser executada e modelada através do Estado e atreladas às ideias iluministas.

Mediante os problemas que Portugal enfrentava através do ensino ministrado pelos Jesuítas, Ribeiro (2007, pg. 33) descreve como seria a formação do cidadão mediante intervenção do Estado Português: "a orientação adotada foi de formar o perfeito nobre, agora negociante; simplificar e abreviar os estudos fazendo que um maior número se interesse pelos cursos superiores; propiciar o aprimoramento da língua portuguesa; diversificar o conteúdo, incluindo o de natureza científica; torná-los os mais práticos possíveis” e Solange Aparecida Zotti (2004) complementa afirmando que as reformas Pombalinas possuíam um caráter inovador, principalmente no que tange a educação, onde os avanços possuíam caráter científico. $\mathrm{Na}$ verdade, Pombal tentara implementar em Portugal um modelo econômico e educacional já existente na Inglaterra, baseado no capitalismo. Ribeiro (2007, pg. 35) descreve este episódio afirmando que "as Reformas Pombalinas visavam transformar Portugal numa metrópole capitalista, a exemplo do que a Inglaterra já era há mais de um século”.

Com a descoberta de metais preciosos na colônia como ouro, por exemplo, há um enorme contingente principalmente de portugueses que migraram para a colônia para explorar 


\section{(titinerarius \\ vol. 2-n. 13-2012 \\ Revista Eletróniéa do Curse de Pedaugoúa

os metais valiosos, o que segundo Zotti (2004) fez com que a população "livre" fosse mais abundante que a população "escrava". Surge um grande problema: Zotti (2004, pg. 27) afirma que no momento em que população mais necessitava de plano para a educação "em virtude de sua urbanização e da diversificação das atividades econômicas", os Jesuítas são expulsos da colônia e a mesma fica desolada. Além disso, a reforma apresentada por Pombal, na colônia Brasileira, não foi como se esperava, pois "Somente em 1772, treze anos após a expulsão dos jesuítas e do alvará de 28 de junho de 1759, é que foram estabelecidas as aulas de primeiras letras, de gramática, de latim e de grego no Rio de Janeiro e nas principais cidades das capitanias (ZOTTI apud AZEVEDO, 1976; RIBEIRO, 1998)".

As reformas educacionais implantadas promovidas por Pombal no Brasil eram baseadas nas "aulas régias",

As aulas régias, baseadas no enciclopedismo, constituíam-se em unidades de ensino,
com professor único, instalada para determinada disciplina, que deveriam substituir
as disciplinas antes oferecidas nos colégios Jesuítas. Eram aulas autônomas e
isoladas, não havendo um currículo, no sentido de um conjunto de estudos
ordenados e hierarquizados, nem a duração prefixada se condicionava ao
desenvolvimento de qualquer matéria (ZOTTI, 2004, pg. 28 apud CHAGAS, 1980,
pg. 09).

Ribeiro (2007, pg. 34) relata que "pedagogicamente esta nova organização é um retrocesso, apenas representou um avanço ao exigir novos métodos e novos livros”. Essas aulas não foram nem de longe uma unanimidade dentro da colônia, primeiro porque estas atendiam uma minoria elitizada no qual esta se preocupava apenas em obter o mínimo de instrução necessária para continuar seus estudos em centros Europeus, principalmente, na Universidade de Coimbra. Além disso, como aponta Zotti (2004, pg. 27), "também continua inexistente um projeto de educação popular". Isto evidencia claramente que Portugal não tinha interesse em instruir de forma ampla habitantes da colônia, já que os mesmos teriam que migrar para Europa para desta forma dar continuidade aos seus estudos. Além disso, Lombardi \& Nascimento (2004, pg. 45) afirmam que "os professores régios não tinham uma formação escolar específica como pré-requisito para sua nomeação". Sendo assim, ficava impossível de se ter uma educação de qualidade, com profissionais mal qualificados.

\footnotetext{
${ }^{5}$ Mais informações a respeito podem $\quad$ ser acessadas no link < http://educerepedagogia.blogspot.com.br/2011/08/reformas-pombalinas-aulas-regias-e.html>. Acesso em: 28 ago. 2012.
} 


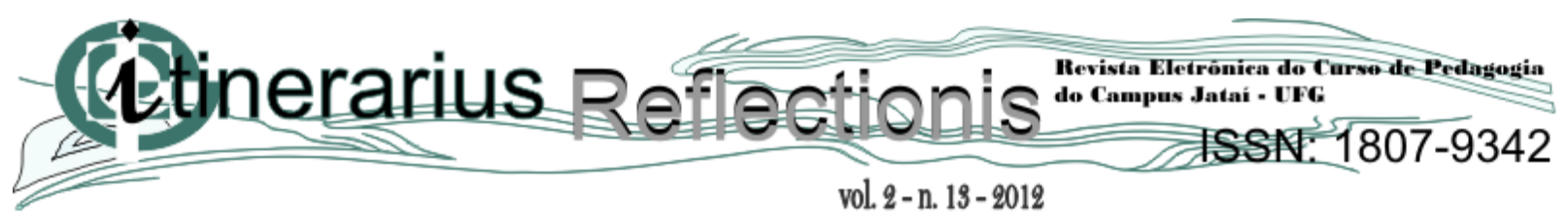

Evidentemente, para criar e instalar esta nova 'percepção' de ensino instituído por Pombal e pelo Estado são necessários investimentos, porém somente em 1772 criou-se um imposto para suprir estas necessidades. Este tributo ficou conhecido como "subsídio literário"

\begin{abstract}
Institui-se o "subsídio literário" (imposto colonial criado em 1772 para custear o ensino), o número de aulas alcançou alguma diversificação em matérias como retórica. Hebraico, matemática, filosofia e teologia. Tudo, porém, muito precário em virtude da escassez de recursos, de docentes despreparados e da inexistência de um currículo regular com objetivos claramente definidos (ZOTTI, 2004, pg. 29).
\end{abstract}

Como se percebe, esta prática adotada pelo governo Português é bem semelhante às práticas governamentais dos atuais Governantes Brasileiros. O que se tem na verdade é um desmantelamento de toda uma estrutura de ensino já existente na colônia, que foi desarticulada politicamente, por um Burocrata que se quer conhecia as condições da colônia portuguesa. Conclusão disso tudo, é que a reforma proposta por Pombal foi um desastre e a educação passou por momentos de 'trevas' neste período.

Hoje em nosso país ainda temos estas políticas educacionais que são escritas em gabinetes e que quando são aplicadas não funcionam. Isto se deve como já explicitado acima, na maioria das vezes, a falta de conhecimento dos burocratas em verificar a aplicabilidade de certas políticas educacionais em sua prática. Conclusão disso tudo é que o Brasil passou por mais de meio século sem investimentos educacionais concretos, sem acompanhar os progressos que de fato aconteceram neste século, principalmente na Europa. Como afirma Zotti (2004, pg. 32) "restam no Brasil, na educação, as aulas régias para a formação mínima dos que iriam ser educados da Europa".

\title{
Período Joanino
}

"No final de século XVII e início do século XIX, o mundo passa por numerosas transformações desencadeadas pela Revolução Francesa, em 1789, e pela Revolução Industrial, cujo berço foi a Inglaterra", (ZOTTI, 2004, pg. 33). Mas o que isso tem a ver com o período Joanino? Este período teve início em 1808 quando a família Real Portuguesa, ente eles D. João Rei de Portugal, (daí o nome período Joanino) desembargou em terras Brasileiras e por lá ficou até 1821 quando os conflitos na Europa cessaram. Era período de revoluções na 


\section{(1tinerarius \\ vol. 2-n. 13-2012 \\ Revista Eletróniéa do Curse de Pedagogia

Europa, como Solange Aparecida Zotti afirma. O continente Europeu passava por transformações profundas. De um lado a França, com a Revolução Francesa, de outro a Inglaterra, maior potencial mundial da Época com a Revolução Industrial. Em busca de mercados estas potências acabam se confrontando e abalando a economia do velho continente, afetando Portugal. Isto faz com que a família Real Portuguesa em basca de refúgio procure terras Brasileiras a fim de se salvar dos conflitos na Europa. Como Portugal tinha relações comerciais muito próximas com a Inglaterra, isto faz com que Portugal abra os portos Brasileiros para os Ingleses, expandindo os negócios na colônia e forçando o Rei de Portugal a investir na até então esquecida colônia. Esses investimentos aconteceram em vários setores da economia Brasileira, e também é claro na Educação.

Por mais de trezentos anos a colônia clamou por melhores condições de infraestrutura e educação, pois as reformas Pombalinas não surtiram efeito no Brasil, aliás, a educação neste período fora um desastre, sendo reduzida a 'praticamente nada'. Com a chegada da família real na colônia, o Brasil, como descreve Zotti (2004, pg. 34), ganhou-se "um estado transplantado, similar ao Estado Português", ou seja, começou-se a implantar no Brasil um sistema político similar ao que já existia em Portugal, não obstante, isto significou "a porta de entrada para a independência da colônia, que viria a se concretizar politicamente em 1822”, (ZOTTI, 2004, pg. 33).

Diversas medidas foram adotadas, que acabaram por de certa forma a influenciar o intelecto da futura nação. Pode-se destacar: "Criação da Imprensa Régia em 13/05/1908; Biblioteca Pública do Jardim botânico do Rio de Janeiro, em 1810, aberta ao público em 1814; Museu Nacional em 1818 e Primeiro jornal - A gazeta do Rio em 1808” (ZOTTI, 2004 apud AZEVEDO, 1976).

Havia também a necessidade de melhorar a segurança da colônia, pois as circunstâncias em que se encontrava a mesma, com a iminente possibilidade de invasões, esta não era segura para proteger a família Real. Desta forma, algumas medidas emergenciais foram adotadas. Dentre elas destaca-se:

Toda a frota portuguesa, mercante e de guerra, pôs-se a salvo no Brasil, gerida, então, pelo recém-criado Ministério de Negócios da marinha e Ultramar. Foram criados, também, o Ministério de Negócios Estrangeiros e da Guerra e o Arquivo Militar, este com os objetivos de levantar mapas da costa e das fortificações, projetar estradas, estudar a navegação dos portos, rios, e outros assim amplos. Várias unidades militares foram criadas ou recriadas como o Corpo da Brigada Real do 


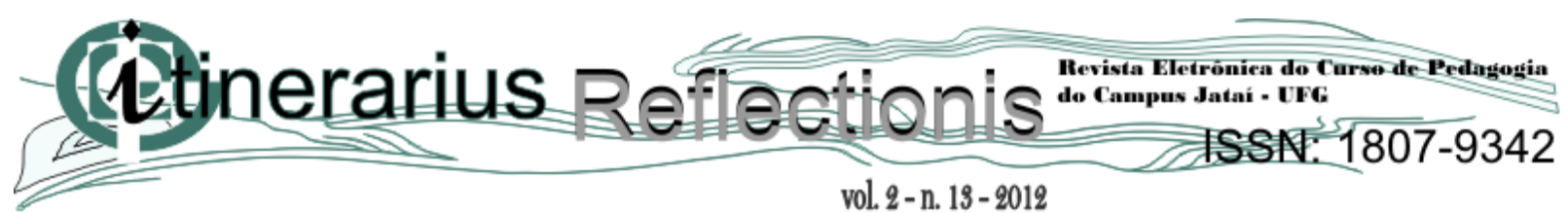

Brasil, a Divisão Militar da Guarda Real da Polícia, o $1^{\circ}$ Regimento da Cavalaria (atual Regimento dos Dragões da Independência), a Brigada Real da Marinha (atual Corpo de Fuzileiros navais). Em 1808 foi criada a fábrica de pólvora, no Rio de Janeiro. Todo esse aparato bélico foi empregado no duplo propósito de hostilizar a França e seus aliados, "para inglês ver", na expressão da época, e promover o expansionismo português. (CUNHA, 2007, pg. 68).

Com as medidas adotadas, estas impulsionaram a economia da colônia de uma maneira nunca antes vista. Houve naturalmente uma demanda de mão de obra qualificada. Para atender a esta demanda o governo interino cria cursos na colônia com o objetivo de formar "profissionais liberais", (ZOTTI, 2004, pg. 35). São eles:

Academia da Marinha e as cadeiras de anatomia e de cirurgia (em 1808); Academia Real Militar (em 1810); o curso de agricultura (em 1814); o curso de desenho técnico (em 1818); a academia de Artes (em 1820). Na Bahia foram criadas as cadeiras de cirurgia e de economia política (em 1808); o curso de agricultura (em 1812); o curso de química (em 1817). Outras cidades abrigaram, também, instituições de ensino superior, como a cadeira de matemática superior, criada em Recife ou Olinda, em 1809, a cadeira de desenho e história, em Vila Rica, em 1817 (CUNHA, 2005, pg. 69).

Entretanto, como afirma Zotti (2004, pg. 35), “continuava a tradição de não preocupação com os demais níveis de ensino, ou seja, o desinteresse completo pela educação do povo (primário e secundário), ficando claro que o objetivo era a educação da elite”. Há claramente um enorme descompasso na educação da colônia. Por um lado, a criação de alguns cursos superiores, mas em contrapartida, D. João não cria novas instituições de ensino capaz de fomentar uma base educacional para que esses alunos ingressem nesses cursos superiores.

O ensino primário continua reduzido a escolas de ler e escrever, sendo criadas mais de 60 cadeiras de primeiras letras. O ensino secundário é composto de cadeiras isoladas (aulas régias), tendo sido criadas pelo menos 20 cadeiras de gramática latina, duas de inglês e uma de francês no rio de Janeiro (ZOTTI, 2004, pg. 35 apud RIBEIRO, 1998).

Evidentemente, as ações de D. João sacudiram a economia do Brasil bem como amenizaram a agonizante situação que se encontrava a educação na colônia, mas foi insuficiente. Apenas a elite da população conseguia estudar. Além disso, verifica-se que as ações de D. João são isoladas, atendendo algumas províncias, como Bahia e o Rio de Janeiro.

\section{Período Imperial}




\section{(titinerarius 20.

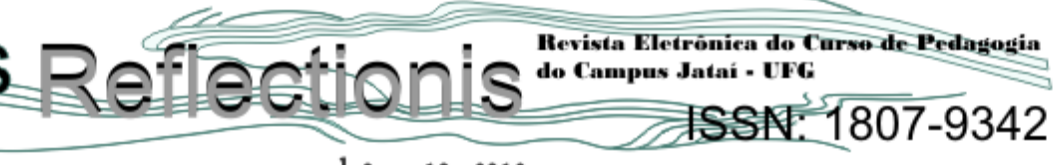 \\ vol. $2-$ n. $13-2012$}

A chegada da família Real no Brasil em 1808 e a abertura dos portos Brasileiros foi o marco inicial para a independência do Brasil em 7 de setembro de 1822. Com a independência da colônia havia uma expectativa muito grande de que reformas educacionais acontecem no País já que este necessitava, mesmo após as mudanças implantadas por D. João, de reformas profundas no sistema educacional. Zotti (2004, pg. 38) afirma que após a independência "os discursos apontavam para a necessidade de se construir um projeto sólido de instrução para garantir a grandeza da nação". Em tese, este discurso é muito importante já que às bases da "grandeza" de uma "nação" se constroem através de uma educação sólida.

Zotti (2004, pg. 38) salienta que as reformas educacionais no país, a princípio, foram inspiradas na "Revolução Francesa" e na "Constituição Francesa de 1791". Foi exatamente com bases nestes princípios que a assembleia constituinte do Brasil inicia os debates acerca da estruturação da educação do País. Há aí o primeiro grande equívoco dos políticos Brasileiros, afinal o Brasil possuía características bem distintas da França e tentar impor no Brasil um sistema educacional baseado em um País que possuía características bem distintas do Brasil, poderia ser inviável, ou até mesmo impossível de aplicá-la. Porém estes debates não passaram desta etapa, pois cerca de seis meses depois de se iniciarem as discussões na Assembleia Constituinte, houve a dissolução da mesma e consequência disto foi que em 1824 houve uma "constituição outorgada" no País, (ZOTTI, 2004, pg. 38). Apenas o artigo 179, parágrafos 32 e 33, tratam da educação no Brasil, descrevendo:

\footnotetext{
A inviolabilidade dos Direitos Civis, e Políticos dos Cidadãos Brasileiros, que tem por base a liberdade, a segurança individual, e a propriedade, é garantida pela Constituição do Império, pela maneira seguinte.

$\$ 32$ - A Instrucção primaria, e gratuita a todos os Cidadãos.

$\S 33$ - Collegios, e Universidades, aonde serão ensinados os elementos das Sciencias, Bellas Letras, e Artes. (BRASIL, 1824).
}

Como nunca houve no Brasil, até aquele período, uma lei se quer que abordasse a educação, pode-se dizer que foi um avanço, porém muito modesto. Por exemplo, quando a constituição cita que "a Instrucção primaria, e gratuita a todos os Cidadãos" salta aos olhos o seguinte questionamento: Quem é responsável por essa "instrução"? O império? Províncias? Municípios? Ora, sabe-se que da forma em que a lei foi escrita tudo se torna um 'jogo de empurra, empurra' e no final nenhuma das instâncias governamentais se responsabiliza pela educação. No parágrafo 33 ocorre o mesmo já que não há citação no mesmo sobre quem se 
responsabilize pelos “Colégios" e "Universidades". É neste sentido que se pode afirmar que a constituição foi muito modesta. Mas, de certa forma isso pode ser explicado. Havia naquela época uma tentativa de elitizar a educação, ou seja, a educação da nação seguiria o interesse das classes dominantes, afinal pensava-se: para que educar o povo?

Durante o período imperial, houve sem sucesso, tentativas de mudar os rumos da educação pública no país. Foram vários decretos e leis na tentativa de impulsionar a educação primária, secundária e superior da nação. Em particular, no ensino primário, estas tentativas não surtiram efeito concreto. Em suma, como será verificado, as classes mais desfavorecidas, os mais pobres, não eram beneficiados por essas leis, mas sim a elite brasileira.

\section{Ensino Primário no Império}

"O decreto imperial de 15 de outubro de 1827 foi à primeira lei de instrução elementar, no Brasil, durante o império e única até 1946”, (ZOTTI, 2004, pg. 39). Este é o tamanho do descaso com a educação "elementar" deste país. Como pode uma nação se fortalecer tendo um tratamento ínfimo como este que foi dado para a educação do Brasil naquela época!?. O que impressiona aqui é que a educação primária é berço para o ensino secundário e sem ela, não há muito que fazer mais adiante. A nação clamava por uma educação na base para atender as mais diferenciadas necessidades, porém isto não se concretizou. Este decreto citado acima afirmava que

\footnotetext{
Em todas as cidades, vilas e lugares populosos haverá escolas de primeiras letras que forem necessárias. (...) Os professores ensinarão a ler, escrever, as quatro operações de aritmética, prática de quebrados, decimais e proporções, as noções mais gerais de geometria pratica, a gramática da língua nacional, os princípios de moral cristã e da doutrina da religião católica e apostólica romana, proporcionados à educação dos meninos; preferindo para o ensino da leitura a Constituição do Império e história do Brasil, (XAVIER, 1980, pg. 53).
}

Veja que este decreto não foi claro em relação aos locais onde deveriam existir as escolas elementares bem como no que tange a matriz curricular do que deveria ser ensinado. A citação acima se refere apenas à educação de "meninos", as "meninas" deveriam receber uma educação diferente. Havia claramente uma separação entre a educação que deveria ser oferecida a ambos os sexos. 


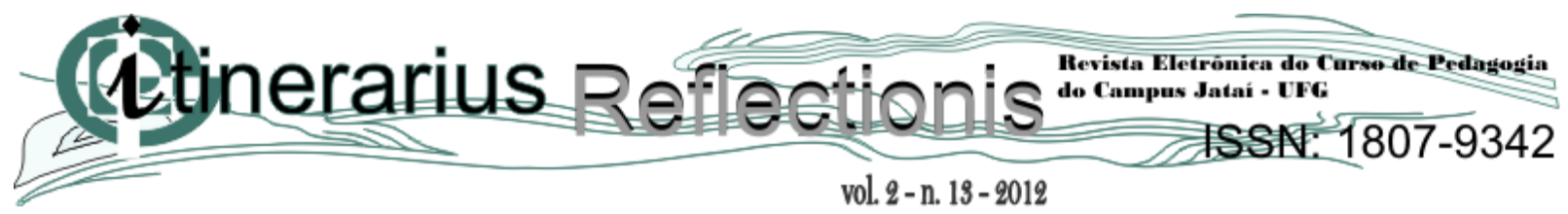

Haverá escolas de meninas nas cidades, vilas e lugares mais populosos em que os presidentes das províncias, em conselho, julgarem conveniente este estabelecimento. As mesmas, além do programa de ensino acima declarado, com exclusão das noções de geometria, e limitando a instrução de aritmética, só as quatro operações, ensinarão as prendas que servem a economia doméstica, (XAVIER, 1980, pg. 54).

Ficam claros os privilégios dos "meninos" sobre as "meninas" na época. Isto fica bem evidente quando se limita o ensino da aritmética e se substitui o ensino da geometria por "prendas domésticas". Esta "segregação" só serve para evidenciar ainda mais o tamanho do descaso com a educação elementar do Brasil naquela época.

Zotti (2004, pg. 40) afirma ainda que "a completa desmotivação com este nível de ensino evidencia-se na adoção do método Lancaster". O que seria este método? Trata-se de um artifício que praticamente eliminava a figura do professor em sala de aula. Este funcionava assim: Os alunos mais avançados se tornavam monitores, estes monitores formavam grupos de estudos que em seguida instruíam seus colegas. Se não bastasse, "os professores que não tiverem a necessária instrução deste ensino, irão instruir-se em curto prazo e a custas de seus ordenados nas escolas das capitais", (MOACYR, 1936, pg. 189). Sendo assim, como os ordenados destes professores eram "irrisórios", (ZOTTI, 2004, pg. 40), este professor não possuía motivação para se qualificar. De fato, o que se tem neste período, na verdade, foi um total descaso com a educação primária do país.

A instrução primária fracassou, pois não se "conseguiu levar a educação geral e comum a todos os pontos do território e de organizá-la em bases uniformes e nacionais", (AZEVEDO, 1971, pg. 566). Durante o império, houve pelo menos mais duas tentativas de modificar a situação calamitosa em que se encontrava a educação primária no Brasil. São eles: “O Decreto no 1.331-A, de 17 de Fevereiro de 1854 que aprova o Regulamento para a reforma do ensino primário e secundário do Município da Corte", (BRASIL, 1854), apresentado por Coutto Ferraz e o "Decreto no 7.247, de 19 de Abril de 1879 onde Reforma o ensino primário e secundário no município da Corte e o superior em todo o Império", (BRASIL, 1879), proposto pelo então Ministro Carlos Leôncio de Carvalho.

Dentre as propostas de reformulação do Ensino para época destacam-se os artigos 47, 48, 49 e 50, do Capítulo III, onde se lê:

Art. 47. O ensino primario nas escolas publicas comprehende: A instrucção moral e religiosa; A leitura e escripta, As noções essenciaes da grammatica; Os principios elementares da arithmetica; O systema de pesos e medidas do municipio. Póde 


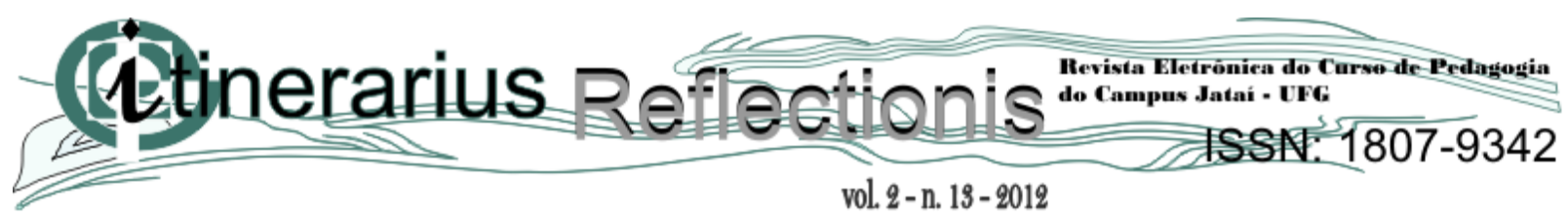

comprehender tambem: O desenvolvimento da arithmetica em suas applicações praticas; A leitura explicada dos Evangelhos e noticia da historia sagrada; Os elementos de historia e geographia, principalmente do Brasil; Os principios das sciencias physicas e da historia natural applicaveis aos usos da vida; A geometria elementar, agrimensura, desenho linear, noções de musica e exercicios de canto, gymnastica, e hum estudo mais desenvolvido do systema de pesos e medidas, não só do municipio da Côrte, como das provincias do Imperio, e das Nações com que o Brasil tem mais relações commerciaes.

Art. 48. As escolas publicas primarias serão divididas em duas classes. A huma pertencerão as de instrucção elementar, com a denominação de escolas do primeiro gráo. A outra as de instrucção primaria superior com a denominação de escolas do segundo gráo.

Art. 49. O ensino nas do primeiro gráo será restrictamente o que se acha marcado na primeira parte do Art. 47: nas do segundo gráo comprehenderá demais as materias da segunda parte do mesmo Artigo, que por deliberação do Governo, sobre proposta do Inspector Geral, e ouvido o Conselho Director se mandarem adoptar.

Art. 50. Nas escolas para o sexo feminino, alêm dos objectos da primeira parte do Art. 47, se ensinarão bordados e trabalhos de agulha mais necessarios. (BRASIL, 1854).

Veja que ainda assim, não ficavam claros quais seriam os responsáveis pela educação no império. O governo Central? Os Municípios da Corte? Ou as Províncias? Mesmo que este decreto represente melhora significativa em relação à constituição de 1824 , outorgada por D. Pedro I, apresentando detalhes que não foram descriminados na constituição de 1824, ainda sim, pode-se afirmar claramente que certamente foi insuficiente para melhorar a educação no Brasil império. Por exemplo, há apenas uma descrição de conteúdos a serem trabalhados, porém sem uma matriz curricular especifica. Ainda há uma segregação de sexos impostas pelo governo central, como mostra Art. 50: Haverá escolas de "sexo feminino (...) se ensinarão bordados e trabalhos de agulha mais necessários". Além disso, Zotti (2004, pg. 42) descreve que "a maioria dos dispositivos dessa lei não foram cumpridos. A classe elementar teve reduzida implementação e o ciclo superior nem saiu do papel”. Infelizmente, esta é uma herança 'maldita' em que até hoje somos agraciados com enxurradas de leis que são elaboradas pelos parlamentares e que jamais são cumpridas.

A última reforma do Império foi feita, através do Decreto nº 7.247, de 19 de Abril de 1879. Sem dúvida esta lei foi a mais inovadora de todas. Este documento, de acordo com Zotti (2004, pg. 43), "foi inspirado nos Estados Unidos, leva a termo o espírito liberal, baseado na filosofia da educação de Rousseau e da Revolução Francesa”.

Já em seu Art. $1^{\circ}$ tem-se que "é completamente livre o ensino primario e secundario no municipio da Côrte e o superior em todo o Imperio" (BRASIL, 1879). Ou seja, 
não há restrições sobre quem pode estudar deixando claro que o ensino é "completamente livre" para negros, escravos ou para os mais pobres.

No Art. $2^{\circ} \S 1^{\circ}$, previa inclusive multa para os pais ou detentores da guarda de crianças que não estivessem frequentando uma escola, mostrando que o interesse do governo central era que todas as crianças estudassem.

\begin{abstract}
todos aquelles que, tendo em sua companhia meninos ou meninas nas condições acima mencionadas, deixarem de matriculal-os nas escolas publicas, ou de proporcionar-lhes em estabelecimentos particulares ou em suas casas a instrucção primaria do $1^{\circ}$ gráo, sejam pais, mais, tutores ou protectores, ficam sujeitos a uma multa de 20 a $100 \$ 000$, (BRASIL, 1879).
\end{abstract}

Foi estabelecida também a obrigatoriedade do ensino para crianças, meninos e meninas, até os 14 anos de idade. Isto pode ser verificado no Art. $2^{\circ}$ "até se mostrarem habilitados em todas as disciplinas que constituem o programma das escolas primarias do $1^{\circ}$ gráo, são obrigados a frequental-as, no municipio da Còrte, os individuos de um e outro sexo, de 7 a 14 annos de idade", (BRASIL, 1879).

Outro destaque desta lei é que ela previa em seu Art. $5^{\circ}$ que "serão fundados em cada districto do municipio da Côrte, e confiados á direcção de Professoras, jardins da infancia para a primeira educação dos meninos e meninas de 3 a 7 annos de idade", (BRASIL, 1879). Ou seja, além da obrigatoriedade do ensino de crianças de 7 a 14 anos de idade, como já explicitado, este também previa locais de ensino para as crianças menores a fim de preparálas para as séries iniciais do ensino primário.

Para os mais desfavorecidos havia inclusive doação de livros e roupas para que os mesmos pudessem frequentar as escolas públicas. Isto pode ser verificado no Art. $2^{\circ} \S 3^{\circ}$ "aos meninos pobres, cujos pais, tutores ou protectores justificarem impossibilidade de preparal-os para irem á escola, será fornecido vestuario decente e simples, livros e mais objectos indispensaveis ao estudo", (BRASIL, 1879). Estava prevista em lei, inclusive, de que forma seriam feitas estas distribuições de materiais para os alunos mais necessitados, Art. $2^{\circ} \S 3^{\circ}$ : "este fornecimento será feito por ordem do Conselho director da instrucção publica, o qual prestará conta trimensalmente ao Governo, e no fim de cada anno apresentará um calculo approximado do fornecimento necessario para o anno seguinte", (BRASIL, 1879). 


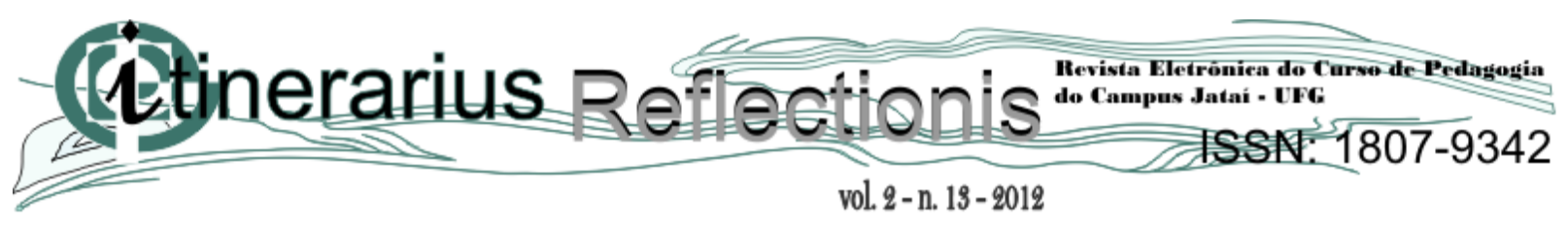

Fica claro até o momento a intenção do governo central, através deste decreto, em alfabetizar um país que por mais trezentos anos não possuiu uma alfabetização coerente para suas crianças. Isto fica evidente quando, de acordo com Art. $8^{\circ} \S 4^{\circ}$, o Governo central pretende "Crear ou auxiliar nas provincias cursos para o ensino primario dos adultos analphabetos", (BRASIL, 1879).

Criou-se também, via decreto, as disciplinas que comporiam a matriz curricular ensino primário. Isto pode ser observado no Art. $4^{\circ}$

\begin{abstract}
O ensino nas escolas primarias do $1^{\circ}$ gráo do municipio da Côrte constará das seguintes disciplinas: Instrucção moral; Instrucção religiosa; Leitura; Escripta; Noções de cousas; Noções essenciaes de grammatica; Principios elementares de arithmetica; Systema legal de pesos e medidas; Noções de historia e geographia do Brazil; Elementos de desenho linear; Rudimentos de musica, com exercicio de solfejo e canto; Gymnastica; Costura simples (para as meninas), (BRASIL, 1879).
\end{abstract}

Contudo, ainda falta destacar que a lei previa criação de museus e bibliotecas. Isto pode ser encontrado no Art. $7^{\circ}$ "Serão creadas nos differentes districtos do mesmo municipio pequenas bibliothecas e museus escolares", (BRASIL, 1879).

Em relação aos profissionais da educação, também pode ser observado que nos artigos 17, 18, 19 este documento regulamenta um plano de carreira para os docentes. Por fim, o decreto indicava uma tabela onde constavam os vencimentos dos profissionais que trabalhariam com a educação (ver Tabela 2).

\begin{tabular}{l|l|l|l}
\hline \multirow{2}{*}{ Empregos } & \multicolumn{3}{|l}{ Vencimentos Anuais } \\
\cline { 2 - 4 } & Ordenado & Gratificação & Total \\
\hline Diretor & $2: 600 \$ 000$ & $1: 400 \$ 000$ & $4: 000 \$ 000$ \\
\hline Professor & $2: 400 \$ 000$ & $1: 200 \$ 000$ & $3: 600 \$ 000$ \\
\hline Substituto & $1: 600 \$ 000$ & $800 \$ 000$ & $2: 400 \$ 000$ \\
\hline Mestre & $800 \$ 000$ & $400 \$ 000$ & $1: 200 \$ 000$ \\
\hline Secretario & $2: 000 \$ 000$ & $1: 000 \$ 000$ & $3: 000 \$ 000$ \\
\hline Amanuense & $1: 200 \$ 000$ & $600 \$ 000$ & $1: 800 \$ 000$ \\
\hline Porteiro & $800 \$ 000$ & $400 \$ 000$ & $1: 200 \$ 000$ \\
\hline Continuo & $500 \$ 000$ & $300 \$ 000$ & $800 \$ 000$ \\
\hline Servente & $\ldots$ & $45 \$ 000$ & $45 \$ 000$ \\
\hline
\end{tabular}

Tabela 2: Vencimentos do Corpo Docente e dos Demais Trabalhadores da Educação Decreto $n^{\circ} 7247$.

Fonte: (BRASIL, 1879). 


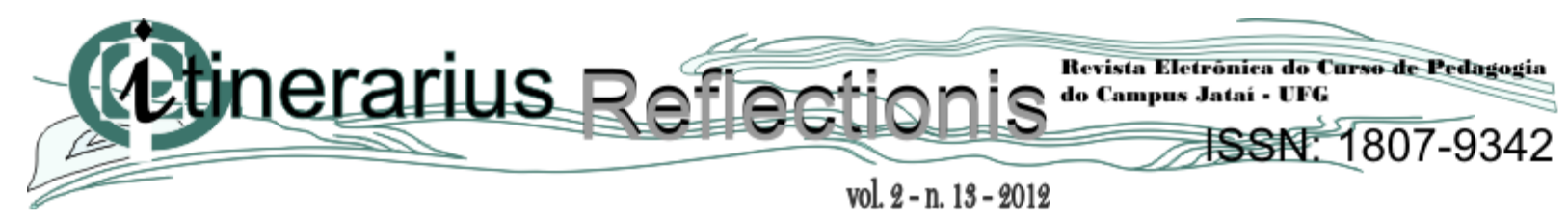

Por fim, após este decreto, houve melhora na educação primária do Brasil? A resposta infelizmente é não. Zotti (2004, pg. 43) afirma que

O império relegou o ensino primário ao descaso completo, ficando as poucas tentativas de aperfeiçoamento reduzidas a leis que nunca foram cumpridas. $O$ currículo aplicado, no sentido do prescrito para ser ensinado, nunca passou de aulas de leitura, escrita e cálculo.

\section{Considerações Finais}

Lamentavelmente, o Brasil herdou desde a época colonial o descaso com a educação em que este país viveu durante sua colonização. Inicialmente, é fato que no princípio da colonização portuguesa no Brasil não havia muito que fazer, porém isso não pode ser exemplo de comparação, caso contrário, Estados Unidos ou Austrália não seriam países ricos e desenvolvidos atualmente. O fato é que quando os padres Jesuítas iniciaram a educação no Brasil, estes na verdade não estavam preocupados de fato com a instrução do povo e sim a procura de adeptos ao catolicismo. Por um tempo isto funcionou, mesmo com infraestrutura precária com seus ensinamentos baseados na leitura e na escrita. Isto pode ser verificado nos relatos de Vanilda Paiva, Maria Luisa Ribeiro e Luis Antônio Cunha. Portugal naquela época era um país atrasado e dotado ainda de práticas feudais. Para se ter uma ideia, na época em que o Brasil foi descoberto "em Portugal o sistema escolar apenas começava a ser montado e que analfabetismo dominava não somente as massas populares e a pequena burguesia, mas se estendia a alta nobreza e a família real”,, (PAIVA, 2003, pg. 67 - 68). Ora, como um país que não possui estrutura educacional adequada irá implantar um modelo de ensino exemplar fora de seu território? Como que um país que nem educa os próprios membros da família real se preocuparia com os menos favorecidos?

A educação tanto no período colonial ou imperial sempre foi uma educação "para as elites" (ZOTTI, 2004, pg. 35). Independente dos avanços que ocorreram no Brasil com a chegada de D. João com a criação de cursos superiores e incentivos a indústria, ou com os decretos que surgiram durante os governos de D. Pedro I e D. Pedro II, sempre houve no Brasil o desinteresse pela educação popular. A sonhada "modernização do ensino", (ZOTTI, 2004, pg. 25), jamais ocorreu e até nos nossos dias atuais ainda estamos ansiando. Espera-se 


\section{Etinerarius Refoctionis 2

vol. 2-n. $13-2012$

realmente uma educação que acolha todas as classes, ricos e pobres, ensino primário, secundário ou superior. Não há mais espaço para escolas o péssimo estado de conservação, salários baixos para os profissionais do ensino, decretos e leis não cumpridas, já que ainda hoje o Brasil tem essas 'tradições' de quase 500 anos atrás com reflexos na educação do país.

Por fim, como Solange Aparecida Zotti destaca "De fato a elite nunca teve interesse por esse nível de ensino, e o povo... Ora, para que educar o povo..." (p. 43).

\section{REFERÊNCIAS}

AZEVEDO, F. A cultura Brasileira, v. 13, 1971. Edições Melhoramentos.

BRASIL. Constituição Política do Império do Brasil (25 de Março de 1824). Disponível em: <http://www.planalto.gov.br/ccivil_03/constituicao/constitui\%C3\%A7ao24.htm>. Acesso em: 05 set. 2012.

Decreto $\mathrm{n}^{\mathrm{o}} 1.331$-A, de 17 de Fevereiro de 1854. Aprova o regulamento para a Reforma do Ensino Primário e Secundário no Município e na Corte. Disponível em: <http://www2.camara.gov.br/legin/fed/decret/1824-1899/decreto-1331-a-17-fevereiro-1854590146-publicacaooriginal-115292-pe.html>. Acesso em: 07 set. 2012.

Decreto $\mathrm{n}^{\mathbf{0}}$ 7.247, de 19 de Abril de 1879. Reforma o Ensino Primário e Secundário no Município da Corte e o Superior em Todo o Império. Disponível em: <http://www2.camara.gov.br/legin/fed/decret/1824-1899/decreto-7247-19-abril-1879547933-publicacaooriginal-62862-pe.html>. Acesso em: 07 set. 2012.

CUNHA, L. A. C. R. A Universidade Temporã: O Ensino Superior, da Colônia à Era Vargas. 3. ed. [revista]. São Paulo: UNESP, 2007. UNESP, 2005.

O Ensino de Ofícios Artesanais e Manufatureiros no Brasil Escravocrata,

D’AMBROSIO, U. História da matemática no Brasil uma Visão Panorâmica até 1950. Disponível em: <http://vello.sites.uol.com.br/historia.htm>. Acesso em: 27 ago. 2012.

KARINA, H. C. A Educação em seu Contexto Histórico: Desafios da Educação Pública Brasileira Frente ao Terceiro Milênio. Publicado em 08/04/2009. Disponível em: $<$ http://www.webartigos.com/artigos/a-educacao-em-seu-contexto-historico-desafios-daeducacao-publica-brasileira-frente-ao-terceiro-milenio/16486/\#ixzz26UDqQRta>. Acesso em: 14 set. 2012. 
LOMBARDI, J. C. \& Nascimento, M. I. M. Fontes História e Histografia da Educação. Campinas - SP, 2004 - (Coleção Memória da Educação).

MOACYR, P. A instrução e o Império: (Subsídios para a História da educação no Brasil), vol. 66, 1936, Companhia editora nacional.

PAIVA, V. P. Educação Popular e Educação de Adultos: Contribuições à História da Educação. Edições Loyola, 6. ed. Revista e ampliada. São Paulo, 2003.

PRADO JÚNIOR, C. História Econômica do Brasil. 11. ed. São Paulo: Brasiliense, 1969.

RIBEIRO, M. L. S. História da educação brasileira: a organização escolar. 20. ed. Campinas: Autores Associados, 2007.

SAVIANI, D., et. al. O Legado Educacional no Brasil no Século XX. 2. ed. Campinas - SP: Autores Associados, 2006. Coleção Educação Contemporânea.

XAVIER, M. E. S. P. Poder Político e Educação de Elite. Cortez, 1980.

ZOTTI, S. A. O Currículo no Brasil Colônia: Proposta de Uma Educação Para a Elite. Disponível em: <http://periodicos.uesb.br/index.php/praxis/article/view/383/413>. Acesso em: 30 ago. 2012.

ZOTTI, S. A. Sociedade de educação e currículo no Brasil: dos Jesuítas aos anos de 1980. Campinas-SP: Autores Associados, Brasília - DF, Ed. Plano, 2004. 